AperTO - Archivio Istituzionale Open Access dell'Università di Torino

\title{
Liver transplantation for symptomatic centrohepatic biliary cystadenoma
}

\section{This is a pre print version of the following article:}

Original Citation:

Availability:

This version is available http://hdl.handle.net/2318/84071

since 2016-11-11T09:56:39Z

Published version:

DOI:10.1016/j.clinre.2011.03.014

Terms of use:

Open Access

Anyone can freely access the full text of works made available as "Open Access". Works made available under a Creative Commons license can be used according to the terms and conditions of said license. Use of all other works requires consent of the right holder (author or publisher) if not exempted from copyright protection by the applicable law. 
Gastroenterology

Elsevier Editorial System(tm) for Clinics and Research in Hepatology and

Manuscript Draft

Manuscript Number: GCB-D-11-00004R1

Title: Liver transplantation for symptomatic centrohepatic biliary cystadenoma.

Article Type: Clinical challenge

Corresponding Author: Dr. Renato Romagnoli, M.D.

Corresponding Author's Institution: A.O.U. San Giovanni Battista di Torino

First Author: Renato Romagnoli, M.D.

Order of Authors: Renato Romagnoli, M.D.; Damiano Patrono, M.D.; Gianluca Paraluppi, M.D.; Ezio

David, M.D.; Francesco Tandoi, M.D.; Paolo Strignano, M.D.; Francesco Lupo, M.D.; Mauro Salizzoni, M.D.

Abstract: ABSTRACT

Biliary cystadenoma is a rare benign cystic tumor of the liver. The mainstay of treatment is complete resection, either by enucleation or by formal hepatectomy, since incomplete removal entails not only constant recurrence but also the risk of malignant transformation to cystadenocarcinoma. A case of symptomatic centrohepatic biliary cystadenoma involving the main vasculo-biliary structures of the liver is reported. After an unsuccessful attempt at resection resulting in an intrahepatic biliary injury, relief of jaundice and radical excision were achieved by total hepatectomy and liver transplantation. The patient is now alive and well 4 years after transplant disease-free, with normal liver and renal function while receiving everolimus monotherapy. This is the first report of liver transplantation performed for the treatment of this tumor. With the case on the background, diagnostic aspects and available therapeutic strategies for biliary cystadenoma are reviewed and discussed.

Suggested Reviewers: Vincenzo Mazzaferro MD

Chief Surgeon, Liver Transplant and Digestive Surgery, Istituto Nazionale Tumori Milano - Italy vincenzo.mazzaferro@istitutotumori.mi.it

Internationally reknown expert in both transplant and liver surgery for hepatic neoplasms

Opposed Reviewers: 
e-component
Click here to download e-component: Revision Letter.doc

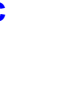

(2) 


\title{
Liver transplantation for symptomatic centrohepatic biliary cystadenoma.
}

\author{
Renato ROMAGNOLI, MD, FEBS, Damiano PATRONO, MD, Gianluca \\ PARALUPPI, MD, Ezio DAVID, MD, Francesco TANDOI, MD, Paolo \\ STRIGNANO, MD, Francesco LUPO, MD, and Mauro SALIZZONI, MD
}

\author{
General Surgery 8 and Liver Transplantation Center, \\ University of Turin, A.O.U. San Giovanni Battista, \\ Turin, ITALY
}

Original article

\section{Category: Clinical Challenges}

\begin{abstract}
Running head : liver transplantation for centrohepatic biliary cystadenoma
Key words : symptomatic biliary cystadenoma, unresectable biliary cystadenoma, complete excision, resectional liver surgery, liver transplantation
\end{abstract}

Disclaimer: nothing to disclose

Word count: 2,584

Address for reprints and correspondence :

Mauro SALIZZONI, MD

Professor of Surgery at the University of Turin Head of General Surgery 8 and Liver Transplantation Center

A.O.U. San Giovanni Battista

Corso Bramante 88

10126 Turin - ITALY

Phone : \# 39.011.6334374

Fax : \# 39.011.6965923

E-mail : mauro.salizzoni@unito.it 


\title{
LIST OF ABBREVIATIONS
}

\author{
BCA, biliary cystadenoma \\ $\mathrm{BCC}$, biliary cystadenocarcinoma \\ $L T$, liver transplantation \\ CA 19-9, carbohydrate antigen 19-9 \\ $\alpha-F P$, alpha-fetoprotein \\ CEA, carcino-embryonic antigen \\ POD, postoperative day
}

R. Romagnoli et al. - 2 
R. Romagnoli et al. - 3

\begin{abstract}
Biliary cystadenoma is a rare benign cystic tumor of the liver. The mainstay of treatment is complete resection, either by enucleation or by formal hepatectomy, since incomplete removal entails not only constant recurrence but also the risk of malignant transformation to cystadenocarcinoma. A case of symptomatic centrohepatic biliary cystadenoma involving the main vasculo-biliary structures of the liver is reported. After an unsuccessful attempt at resection resulting in an intrahepatic biliary injury, relief of jaundice and radical excision were achieved by total hepatectomy and liver transplantation. The patient is now alive and well 4 years after transplant, disease-free, with normal liver and renal function while receiving everolimus monotherapy. This is the first report of liver transplantation performed for the treatment of this tumor. With the case on the background, diagnostic aspects and available therapeutic strategies for biliary cystadenoma are reviewed and discussed.
\end{abstract}


R. Romagnoli et al. - 4

\section{INTRODUCTION}

Biliary cystadenoma $(B C A)$ is a rare benign tumor of the liver presenting usually as a large multiloculated cyst containing a variably coloured mucinous fluid. Histological examination reveals a limiting mucus-secreting cuboidal or columnar epithelium of biliary origin, frequently surrounded by a mesenchymal "ovarian-like" stroma $[1,2]$. When symptomatic, most frequent complaints include abdominal pain, mass effect, nausea and vomiting $[3,4]$. Occasionally BCAs can determine obstructive jaundice [5]. Owing to their origin and size, BCAs are frequently located close to the main hepatic vascular structures and can involve the bile ducts $[1,5,6,7,8,9]$. Curative treatment is based on complete excision, by either enucleation or formal hepatic resection, because incomplete removal implies constant recurrence and risk of malignant transformation to biliary cystadenocarcinoma (BCC) $[4,6,10]$.

In this paper, a case of BCA is illustrated in which relief of symptoms and complete excision could eventually be obtained in no other way than total hepatectomy and liver transplantation (LT). To our knowledge, this is the first report of LT performed for this indication. In the light of this case, diagnostic aspects and currently available therapeutic strategies for BCA are reviewed and discussed.

\section{CASE REPORT}

A 53-year-old woman was referred to our tertiary care center from a country hospital in October 2006 because of the discovery of a large lesion, $10 \mathrm{~cm}$ in diameter, centrally located in the liver across segments 4 and 8 . She had a recent history of obstructive jaundice in the absence of abdominal symptoms. Magnetic resonance and computed 
R. Romagnoli et al. - 5

tomography imaging revealed a cystic mass with some septations in its caudal portion, lying on the Glissonian bifurcation and causing dislocation of the porta hepatis and compression of the main right and left hepatic ducts with peripheral bile duct dilatation (fig.1). On admission, total and conjugated bilirubin were 11.3 and $8.5 \mathrm{mg} / \mathrm{dl}$, respectively, aspartate aminotransferase $77 \mathrm{U} / \mathrm{L}$, alanine aminotransferase $137 \mathrm{U} / \mathrm{L}$, gamma-glutamyltranspeptidase $107 \mathrm{U} / \mathrm{L}$, alkaline phosphatase $357 \mathrm{U} / \mathrm{L}$. Serum chemistries otherwise revealed normal liver function and normal carbohydrate antigen 19-9 (CA 19-9), alpha-fetoprotein ( $\alpha-F P)$ and carcino-embryonic antigen (CEA) levels. Serological testing for echinococcal disease was negative and she did not originate from an endemic area. Based on preoperative findings a clinical diagnosis of intrahepatic BCA was made and she was scheduled for open surgical exploration without delay. On operation, a centrohepatic round mass not abuting on the liver surface was observed. Cholecystectomy was performed and intraoperative cholangiography through the cystic duct stump confirmed external compression on both the right and left hepatic ducts (fig.2A). No communication between the cyst and the biliary tree was noted. The hepatic parenchyma covering the lesion was incised for a $2 \mathrm{~cm}$ depth on the anterior surface of the liver (segments 4-8) searching for a dissection plane along the cystic wall. The attempt at enucleation immediately failed due to the lack of an obvious anatomical plane between the cyst and the parenchyma, obliterated by the presence of dense fibrous tissue. The cyst was accidentally opened and unroofing of the lesion was carried out using a boundary of sponges to protect the abdomen from dissemination of cystic material. A large centrohepatic cavity eventually appeared with some internal septations arising from the floor, containing a mucinous, straw-coloured fluid. The main Glissonian pedicles imprinted the floor of the cavity, indicating strict anatomical relationship 
R. Romagnoli et al. - 6

between the cyst and the hilar plate. Results of frozen section examination of fragments of cystic wall were consistent with the preoperative diagnosis of BCA. After careful drainage and decompression, a second effort to perform enucleation of the lesion resulted in an injury to the right hepatic duct at the anterior/posterior bifurcation, as evidenced by repeated cholangiography. The irregular morphology of the entire intrahepatic biliary tree was patent at this time (fig.2B). A T-tube was inserted into the right hepatic duct through the injured wall. A further attempt to find a dissection plane between the cystic wall and the vasculo-biliary elements of the left hemi-liver failed, due to the ubiquitous presence of dense tissue around the cyst. At that time, continuation of surgery was deemed both useless and unsafe, because of the extensive and bilateral involvement of the main intrahepatic vasculo-biliary structures making radical excision of the BCA technically unfeasible by any type of liver resection (fig.3). The possibility of LT was immediately considered and more material from the cystic wall was obtained for histological examination in order to rule out malignancy. The T-tube was left in place for biliary drainage. Postoperative course was complicated by haemoperitoneum due to bleeding from the dissected intrahepatic areas, which required surgical revision and haemostasis with thrombin glue and filling of the open cavity with an omental flap on postoperative day (POD) 2. Final pathologic examination of the large biopsy samples confirmed the diagnosis of $\mathrm{BCA}$; no areas of intestinal metaplasia or malignant degeneration were observed. Work-up for LT was rapidly completed. She was placed on the waiting list on POD 12, after signing a specific informative consent in which the risks of transplantation (morbidity/mortality of the procedure, need of long-term immunosuppression) were clearly explained in comparison with its expected benefits (complete and permanent relief of jaundice, radical excision of a lesion with a potential 
for cancerous transformation). She was discharged home on POD 16, with the T-tube patent for drainage and a total bilirubin level of $2.8 \mathrm{mg} / \mathrm{dl}$. A whole liver allograft from an AB0-compatible donor after brain death became available in November 2006, i.e. on POD 42 from the first surgery. Abdominal exploration at the time of LT evidenced no sign of extrahepatic dissemination of mucinous material. Omentectomy was performed en bloc with the native liver hepatectomy (fig.3). Transplant surgery was a routine using the piggy-back technique without veno-venous by-pass and the post-transplant course was uneventful with a discharge 7 days after LT. Explant pathology confirmed a cystic lesion lined by a single-layer columnar epithelium lying on a thick mesenchymal "ovarian-like" stroma (fig.4). No areas of malignant transformation were detected, confirming the pre-transplant diagnosis of BCA. She is now 4 years after LT, free from complications and disease recurrence, living a normal life in general good health. Since then, liver graft and renal functions have always remained normal, while immunosuppressive therapy was tapered from an initial scheme based on tacrolimus and mofetil mycophenolate to a current single-drug m-TOR inhibitor regimen (oral everolimus, Certican ${ }^{\circledR}, 2 \mathrm{mg}$ bid to keep 5-6 ng/ml trough levels).

\section{DISCUSSION OF THE INDICATION}

First reported by Keen in 1892 [11], BCAs are usually large, multiseptated cysts limited by a cuboidal or columnar type epithelium. The presence of CA 19-9 in the epithelial layer evidenced by immunohistochemical analysis suggests their biliary origin [2]. The vast majority of BCAs are mucinous cystadenomas [2] and occur mostly in middle-aged females. About $85 \%$ of BCAs are surrounded by an "ovarian-like" stroma rich in spindle- 
R. Romagnoli et al. - 8

shaped cells with prominent nucleoli; such stroma is observed only in females [12]. Reported incidence of BCAs is $5 \%$ of all hepatic cysts based on an autopsy series of 1977 [13]. If for Regev [14] BCAs represent $11 \%$ of all large ( $\geq 4 \mathrm{~cm}$ ) hepatic cysts referred for treatment, their finding remains definitely rare. Over the last 12 years, more than 1500 LTs and nearly 1000 liver resections were performed in our tertiary referral center in Northern Italy; yet, only 6 cases of BCA were encountered [personal unpublished data]. The presence of intestinal metaplasia of the epithelium constitutes the first sign of progression towards malignant BCC, which is finally characterized by the loss of epithelial architecture and nuclei stratification, cellular pleomorphism and infiltration of the underlying stroma [3]. Prevalence of BCC in the published series is highly variable ranging from 5 to $40 \%$ of all BCAs $[1,2,3,10]$.

The most frequently referred symptom is abdominal pain, which is reported by $54-80 \%$ of patients $[3,8,10,15,16]$. Other symptoms include abdominal fullness or distension, anorexia, nausea and vomiting. Less frequently BCAs present with intracystic haemorrhage, intraperitoneal rupture or secondary infection. Inferior vena cava thrombosis due to mass effect has also been described [15]. Obstructive jaundice can result either from external compression or from polypoid protrusion of the lesion into the bile ducts [5,17]. Diagnosis is based mainly on radiological studies. BCAs appear typically as large multiloculated lesions with internal septations; sometimes a thickened wall presenting contrast-enhancement is observed $[18,19,20]$. Unfortunately, imaging is poorly specific in discriminating BCA from BCC, even if the finding of internal papillary vegetations may raise the concern for malignant degeneration. Serum $\alpha-F P$ and CEA levels are usually within normal values, while CA 19-9 levels can be elevated both in BCA and BCC [7]. Percutaneous aspiration and analysis of cyst fluid often reveals a 
R. Romagnoli et al. - 9

marked but variable elevation in CA 19-9 levels, consistent with the biliary origin of the cyst epithelium [21,22]. Cyst fluid CA 19-9 levels can help in differential diagnosis between BCA and hydatid or simple cysts, as they are usually normal or minimally elevated in the latter [21], but cannot help distinguish between BCA and BCC. If cyst fluid cytology can reveal the presence of atypical cells, false negative results are frequent since the technique often fails to retrieve malignant cells in case of BCC [7]. Therefore, cyst fluid analysis can be considered in the differential diagnosis with other cystic liver lesions, but has no role in discriminating BCA from BCC. Furthermore, it presents the theoretical risk of tumour seeding, with one well-documented case of pleural carcinomatosis following percutaneous aspiration of a BCC [7]. Finally, intraoperative examination of frozen sections was not completely reliable in some series $[4,23,24,25]$, in which it resulted negative for a BCC that was discovered afterwards on the formalin-fixed specimen. This is why final pathology report is needed before making any further prognostic judgement and therapeutic decision.

Appropriate surgical treatment of BCA, which is the 'cholangiocellular' counterpart of the much more frequent 'hepatocellular' adenoma, is based on the same principle of complete resection, either by enucleation or hepatectomy [26,27,28]. In fact, fenestration, marsupialization, aspiration, sclerosis, internal Roux-en-Y drainage and partial resection are followed by constant recurrence $[4,6,28,29]$. Complete resection is mandatory also because diagnosis of BCC can be an incidental one, i.e. made only on histological analysis of the surgical specimen [10]. In our experience all the six BCAs were excised completely, 5 by resectional surgery (4 partial hepatectomies, 1 enucleation) and 1 by LT, with no recurrence at current follow-up [personal unpublished data]. Radical surgical excision of BCAs involving major bile ducts and determining 
obstructive jaundice can be technically challenging, requiring a major hepatic resection sometimes associated with hepaticojejunostomy. Erdogan [5] described a series of 5 patients (4 cystadenoma and 1 cystadenocarcinoma) presenting obstructive jaundice. Jaundice was intermittent in three patients and constant in two. In two patients obstruction was caused by a polypoid protrusion inside the bile ducts, in three by external compression. Communication between the cystic lesion and the biliary tree was noted in only one patient. All of them were successfully managed by complete resection of the lesion which required hepatectomy alone or associated with hepaticojejunostomy. In the series reported by Koffron [23] three of 34 patients had jaundice and were managed either by hepatic resection alone ( 2 patients) or by bisegmentectomy combined with hepaticojejunostomy. Successful management of large centrohepatic BCAs involving main vascular structures by enucleation of the lesion following the plane immediately close to its wall has been reported. A dissection plane can often be identified after drainage and decompression of the cyst [6,29]. In the absence of such plane (making for a BCA unresectable in totality), some Authors have recently published good results with partial or nearly-total resection associated with fulguration of the remnant inner epithelium with Argon beam coagulator [10,23]. However, outcomes of this procedure need further evaluation in the long run because partial resection entails not only the risk of recurrence, but also the possibility to leave in place pathologic tissue liable to undergo subsequent malignant transformation $[4,30]$. In this context, the existence of a cystadenoma-cystadenocarcinoma sequence can be postulated on the basis of the facts that approximately one third of BCCs present areas of benign epithelium and that BCC patients are on average 10-15 years older than the BCA ones $[1,2,3]$ 
In the present case, because of the clinical diagnosis of BCA and the peculiar location of the lesion, no attempt at preoperative biliary drainage was undertaken before the first laparotomy. Preoperative portal vein embolization (in view of the possibility of an extended liver resection) was not considered either, not only due to the cholestatic state with jaundice but also for the uncertainty of the type of resection potentially needed. Unfortunately, at surgical exploration, both enucleation and hepatectomy were not feasible. Thick and dense tissue had obliterated the space between the cystic epithelium and the main bilateral vasculo-biliary structures, making the efforts to find a dissection plane to enucleate BCA result in solely an intrahepatic biliary injury. In addition, a partial resection of the cyst with fulguration of the remnant inner epithelium, apart from its inherent risks (technical failure, recurrence and malignant transformation), would not have likely relieved the jaundice in this patient, in whom massive fibrous involvement of the biliary branches was present. These are the reasons why on the first operation LT was evoked as the best solution for the difficult situation. Indeed, LT has become an accepted therapy for end-stage liver disease with overall 1- and 5-year survival rates of $90 \%$ and $81 \%$, respectively [31]. LT for benign hepatic lesions has been described in cases of adenoma and adenomatosis, focal nodular hyperplasia, haemangioma and haemangiomatosis, lymphangiomatosis, mesenchymal hamartoma, polycystic, Caroli's and hydatid diseases. Results in terms of 1- and 5-year survival are similar to those obtained for other indications $[32,33]$.

Regarding the final decision to proceed to LT, on the one hand, the risks associated with transplant surgery and long term immunosuppression were deemed largely "acceptable" for the patient in the lack of any other equally effective treatment. On the other hand, the concern about a potential post-LT recurrence in case of discovery of 
areas of BCC in the explanted liver was counterbalanced by the presence of pre-LT arguments in favour of the benign nature of the lesion (i.e. presentation in a middleaged female with large and multiple formalin-fixed biopsy samples showing BCA with typical "ovarian-like" stroma, and no area of intestinal metaplasia). Therefore, the risk of recurrence of an hypothetical BCC after LT was considered "low" by the transplant team, i.e. comparable with that of recurrence of hepatocellular carcinoma after LT performed within Milan criteria [34]. Moreover, BCCs arising in association with a mesenchymal stroma usually have a less severe clinical course [2] and there are several reports of disease-free survival after complete resection $[5,7,8,9]$.

This report highlights once more the paramount importance of mastering the whole therapeutic armamentarium in liver surgery within the same institution. In fact, only in that setting a correct balance between perioperative risks and expected treatment outcomes can be made, and patients can be provided with the most appropriate surgical treatment. In other words, for subjects who do not present contraindications to LT, it is our conviction that today LT should be preferred to resectional surgery whenever the latter implies high risks with very little chance of success.

In conclusion, the goal to be achieved when treating BCA remains complete excision. In the reported case, LT for symptomatic centrohepatic BCA allowed the removal of the tumor, relief of symptoms and 4-year disease-free survival. However, the benign nature of the lesion and the on-going shortage of organ donors limits the use of LT to the very selected cases of BCA not amenable to other forms of radical surgical therapy.

\section{ACKNOWLEDGMENTS}

The Authors are indebted to Ms Elizabeth Clarke for her kind assistance. 
R. Romagnoli et al. - 13

\section{CONFLICT OF INTEREST DECLARATION}

No potential conflict of interest relevant to this article was reported. 


\section{REFERENCES}

1. Wheeler DA, Edmondson HA. Cystadenoma with mesenchymal stroma (CMS) in the liver and bile ducts. A clinicopathologic study of 17 cases, 4 with malignant change. Cancer 1985; 56: 1434-45

2. Devaney K, Goodman ZD, Ishak KG. Hepatobiliary cystadenoma and cystadenocarcinoma. A light microscopic and immunoistochemical study of 70 patients. Am J Surg Pathol 1994; 18: 1078-91

3. Ishak KG, Willis GW, Cummins SD, Bullock AA. Biliary cystadenoma and cystadenocarcinoma: report of 14 cases and review of the literature. Cancer 1977; 39: 322-38

4. Delis SG, Touloumis Z, Bakoyannis A, Tassopoulos N, Paraskeva K, Athanassiou $\mathrm{K}$, et al. Intrahepatic biliary cystadenoma: a need for radical resection. Eur J Gastroenterol Hepatol 2008; 20: 10-4

5. Erdogan D, Busch ORC, Rauws EAJ, Van Delden OM, Gouma DJ, Van Gulik TM. Obstructive jaundice due to hepatobiliary cystadenoma or cystadenocarcinoma. World J Gastroenterol 2006; 12: 5735-8

6. Vogt DP, Henderson JM, Chmielewski E. Cystadenoma and cystadenocarcinoma of the liver: a single center experience. J Am Coll Surg 2005; 200: 727-33

7. Hai S, Hirohashi K, Uenishi T, Yamamoto T, Shuto T, Tanaka H, et al. Surgical management of cystic hepatic neoplasm. J Gastroenterol 2003; 38: 759-64

8. Oh TH, Kim MH, Lee SK, Seo DW, Lee SS, Kim EY, et al. Thirteen cases of intrahepatic biliary cystadenoma and cystadenocarcinoma: a single center experience. Korean J Gastroenterol 2006; 47: 379-88 
9. Kim HG. Biliary cystic neoplasm: biliary cystadenoma and biliary cystadenocarcinoma. Korean J Gastroenterol 2006; 47: 5-14

10. Thomas KT, Welch D, Trueblood A, Sulur P, Wise P, Gorden DL, et al. Effective treatment of biliary cystadenoma. Ann Surg 2005; 241: 769-73

11. Henson SW Jr, Gray HK, Dockerty MB. Benign tumors of the liver. VI. Multilocular cystadenomas. Surg Gynecol Obstet 1957; 104: 551-54

12. Goodman ZD, Terraciano LM. Tumours and tumour-like lesions of the liver. In: Burt AD, Portmann BC, Ferrel LD, eds. "MacSween's Pathology of the Liver". Philadelphia, PA. Churchill Livingstone, 2007: 789-90

13. Walt AJ. Cysts and benign tumors of the liver. Surg Clin North Am 1977; 57: 449-64

14. Regev A, Reddy KR, Berho M, Sleeman D, Levi JU, Livingstone AS, et al. Large cystic lesions of the liver in adults: a 15-year experience in a tertiary center. J Am Coll Surg 2001; 193: 36-45

15. Lewis WD, Jenkins RL, Rossi RL, Munson L, ReMine SG, Cady B, et al. Surgical treatment of biliary cystadenoma. A report of 15 cases. Arch Surg 1988; 123 : $563-8$

16. Beuran M, Dan Venter M, Dumitru L. Large mucinous biliary cystadenoma with “ovarian-like" stroma: a case report. World J Gastroenterol 2006; 12: 3779-81

17. Gonzalez M, Majno P, Terraz S, Morel P, Rubbia-Brandt L, Mentha G. Biliary cystadenoma revealed by obstructive jaundice. Dig Liver Dis 2009; 41: e11-e13

18. Mortelé KJ, Ros PR. Cystic focal liver lesions in the adult: differential CT and MR imaging features. Radiographics $2001 ; 21: 895-910$ 
R. Romagnoli et al. - 16

19. Palacios E, Shannon M, Solomon C, Guzman M. Biliary cystadenoma: ultrasound, CT, and MRI. Gastrointest Radiol 1990; 15: 313-6

20. Buetow PC, Buck JL, Pantongrag-Brown L, Ros PR, Devaney K, Goodman ZD, et al. Biliary cystadenoma and cystadenocarcinoma: clinical-imaging-pathologic correlation with emphasis on the importance of ovarian stroma. Radiology 1995; 196: $805-10$

21. Thomas JA, Scriven MW, Puntis MC, Jasani B, Williams GT. Elevated serum CA 19-9 levels in hepatobiliary cystadenoma with mesenchymal stroma. Two case reports with immunohistochemical confirmation. Cancer 1992; 70: 1841-6

22. Lee JH, Chen DR, Pang SC, Lai YS. Mucinous biliary cystadenoma with mesenchymal stroma: expressions of CA 19-9 and carcinoembryonic antigen in serum and cystic fluid. J Gastroenterol 1996; 31: 732-6

23. Koffron A, Rao S, Ferrario M, Abecassis M. Intrahepatic biliary cystadenoma: role of cyst fluid analysis and surgical management in the laparoscopic era. Surgery 2004; 136: 926-36

24. Manouras A, Lagoudianakis E, Alevizos L, Markogiannakis H, Kafiri G, Bramis C, et al. Laparoscopic fenestration of multiple giant biliary mucinous cystadenoma of the liver. World J Gastroenterol 2008; 14: 4257-9

25. Hansman MF, Ryan JA Jr, Holmes JH 4th, Hogan S, Lee FT, Kramer D, et al. Management and long-term follow-up of hepatic cysts. Am J Surg 2001; 181: 404-10 
26. Dokmak S, Paradis V, Vilgrain V, Sauvanet A, Farges O, Valla D, et al. A singlecenter surgical experience of 122 patients with single and multiple hepatocellular adenomas. Gastroenterology 2009; 137: 1698-705

27. Dagher I, Franco D. Lésions kystiques du foie et des voies biliaires (en dehors du kyste hydatique). Place de la chirurgie. Gastroenterol Clin Biol 2005; 29: 875-7

28. Limongelli P, Pai M, Damrah O, Lauretta A, Atijosan O, Habib N, et al. Cystic tumors of the biliary tract: a complete excision is crucial. Int Surg 2009; 94: 13640

29. Dixon E, Sutherland FR, Mitchell P, McKinnon G, Najak V. Cystadenomas of the liver: a spectrum of disease. Can J Surg 2001; 44: 371-6

30. Teoh AYB, Simon SM, Lee KF, Lai PBS. Biliary cystadenoma and other complicated cystic lesions of the liver: diagnostic and therapeutic challenges. World J Surg 2006; 30: 1560-6

31. Salizzoni M, Cerutti E, Romagnoli R, Lupo F, Franchello A, Zamboni F, et al. The first one thousand liver transplants in Turin: a single-center experience in Italy. Transpl Int 2005; 18: 1328-35

32. Tepetes K, Selby R, Webb M, Madariaga JR, Iwatsuki S, Starzl TE. Orthotopic liver transplantation for benign hepatic neoplasms. Arch Surg 1995; 130: 153-6

33. Moya Herráiz A, Torres-Quevedo R, Mir Pallardó J. Liver transplantation in patients with benign hepatic lesions. Cir Esp 2008; 84: 60-6 
34. Mazzaferro V, Regalia E, Doci R, Andreola S, Pulvirenti A, Bozzetti, et al. Liver transplantation for the treatment of small hepatocellular carcinomas in patients with cirrhosis. N Engl J Med 1996; 334: 693-9 


\section{LEGENDS TO FIGURES}

Figure 1. CT-scan pictures showing the mass effect exerted by the centrohepatic biliary cystadenoma. Note the dislocation of the left $(A)$ and right $(B)$ Glissonian pedicles and the close relationship with the hilar plate (B, C), determining diffuse biliary tree dilatation. Internal septations inside the cystic mass are visible (D).

Figure 2. A. Intraoperative cholangiography obtained by injection of contrast material through the cystic duct after cholecystectomy: external compression of the primary biliary bifurcation and of the intrahepatic bile ducts is patent (arrows).

B. Intraoperative cholangiography obtained by injection through the Ttube inserted into the injured right bile duct after drainage and decompression of the cyst: extravasation of the contrast medium into the residual cavity and irregular morphology of the intrahepatic biliary tree are apparent.

Figure 3. Photograph of the explanted liver showing a hepatic vein (thin arrow) and internal septations (thick arrow) arising on the floor of the cyst. A 
2

Figure 4. Histological appearance of the lesion in the explant specimen (A, magnification $100 \mathrm{x}$; B, magnification $400 \mathrm{x}$ ). Note that a typical columnar epithelium, with several intracavitary papillary projections (arrows), is lying over a thick "ovarian-like" stroma rich in spindle cells (arrowhead). 

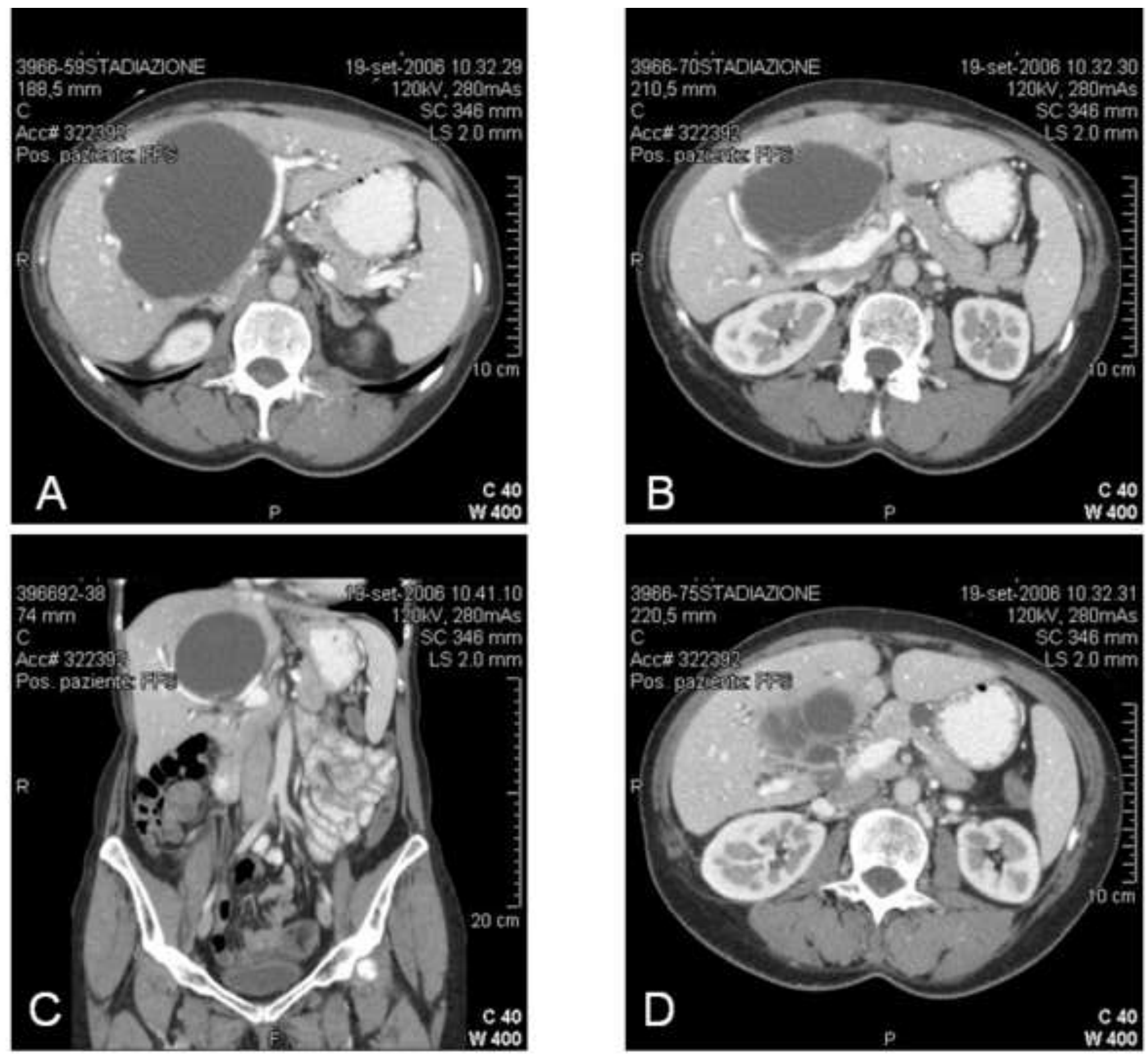
Click here to download high resolution image
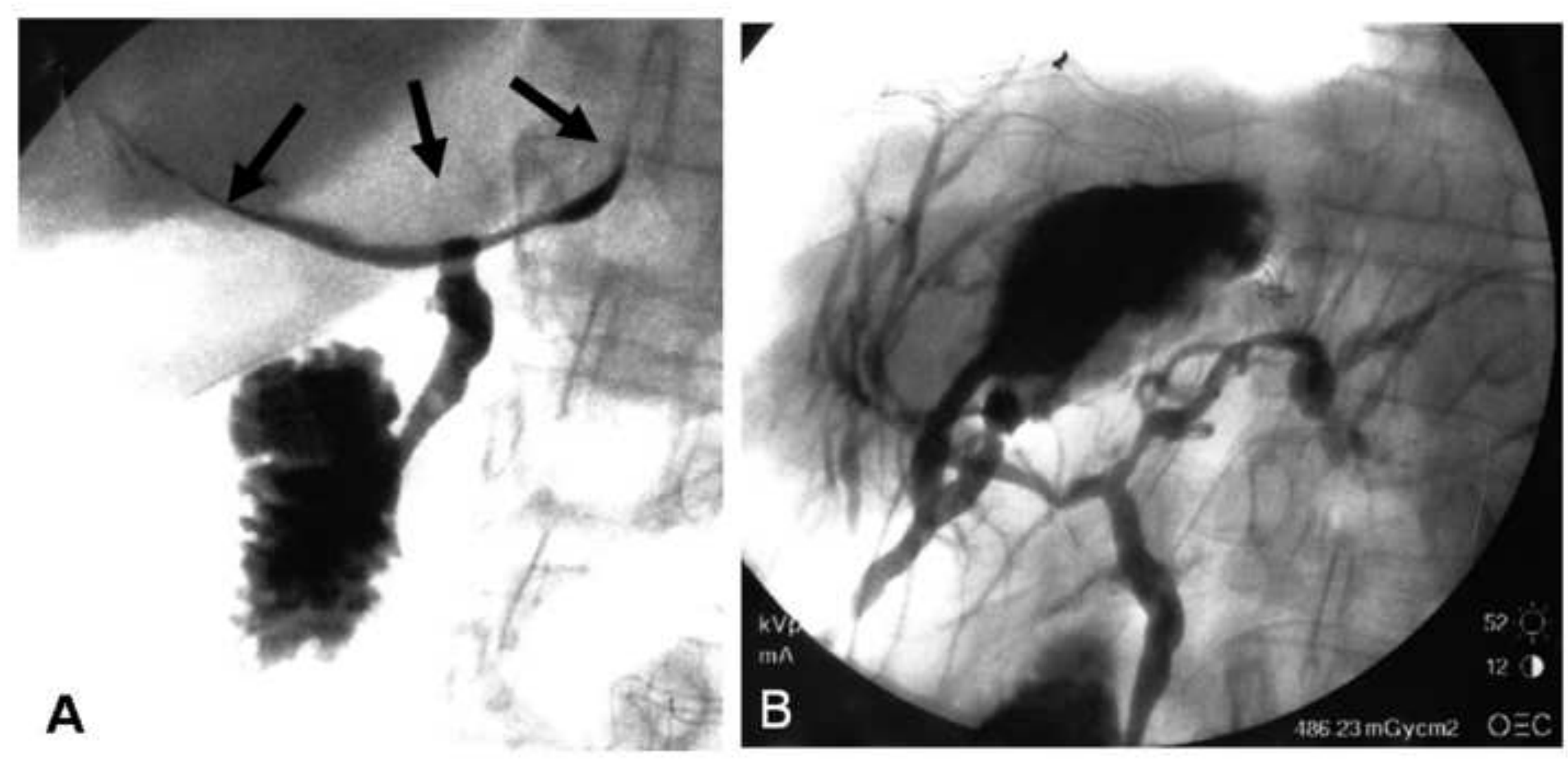
Click here to download high resolution image
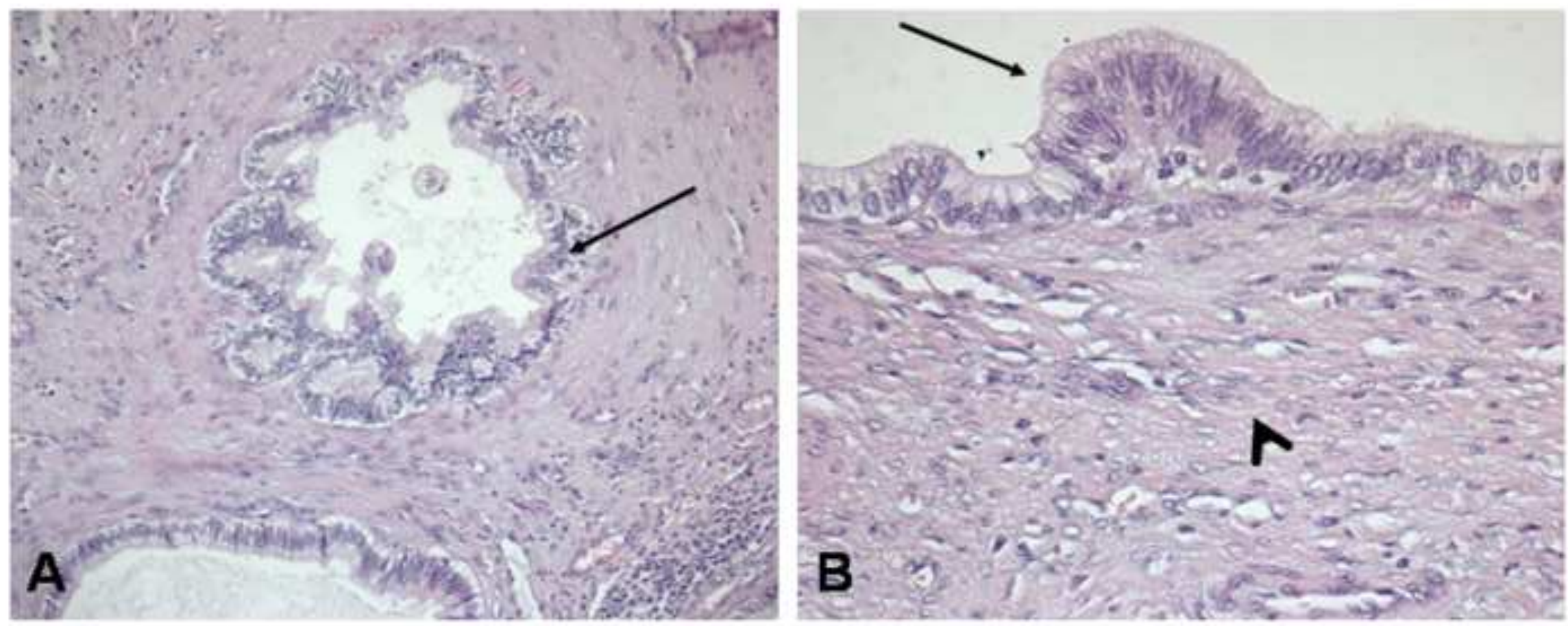